Case Report

\title{
Acute Psychotic Symptoms due to Benzydamine Hydrochloride Abuse with Alcohol
}

\author{
Yahya Ayhan Acar, ${ }^{1}$ Mustafa Kalkan,, ${ }^{2}$ idvan Çetin, ${ }^{2}$ Erdem Çevik, ${ }^{3}$ and Orhan Çınar ${ }^{4}$ \\ ${ }^{1}$ Department of Emergency Medicine, Etimesgut Military Hospital, Etimesgut Asker Hastanesi, Etimesgut, 06797 Ankara, Turkey \\ ${ }^{2}$ School of Medicine, Gulhane Military Medical Academy, GATA Trp Fakültesi, Etlik, 06010 Ankara, Turkey \\ ${ }^{3}$ Department of Emergency Medicine, Van Military Hospital, Van Askeri Hastanesi, Altıntepe, 65040 Van, Turkey \\ ${ }^{4}$ Department of Emergency Medicine, Gulhane Military Medical Academy, GATA Acil Tip AD, Etlik, 06010 Ankara, Turkey
}

Correspondence should be addressed to Yahya Ayhan Acar; yahya_acar@yahoo.com

Received 21 May 2014; Revised 16 August 2014; Accepted 10 September 2014; Published 29 September 2014

Academic Editor: Douglas L. Noordsy

Copyright (c) 2014 Yahya Ayhan Acar et al. This is an open access article distributed under the Creative Commons Attribution License, which permits unrestricted use, distribution, and reproduction in any medium, provided the original work is properly cited.

Benzydamine hydrochloride is a locally acting nonsteroidal anti-inflammatory drug. Benzydamine hydrochloride overdose can cause stimulation of central nervous system, hallucinations, and psychosis. We presented a young man with psychotic symptoms due to benzydamine hydrochloride abuse. He received a total dose of $1000 \mathrm{mg}$ benzydamine hydrochloride with alcohol for its hallucinative effects. Misuse of benzydamine hydrochloride must be considered in differential diagnosis of first-episode psychosis and physicians should consider possibility of abuse in prescribing.

\section{Introduction}

Benzydamine hydrochloride (BH) is a locally acting nonsteroidal anti-inflammatory drug (NSAID) with local anesthetic and analgesic properties for pain relief [1]. $\mathrm{BH}$ is available in capsule form, mouthwash, dermal cream, aerosol, and vaginal douche preparations. Proprietary names of $\mathrm{BH}$ are Tantum (in Austria, Canada, Germany, Italy, The Netherlands, South Africa, Spain, Switzerland, and Turkey), Difflam (in the United Kingdom, Australia), and Opalgyne (in France) [2].

Its reported side effects are urticaria, erythema, rash, photosensitivity, bronchospasm, and renal dysfunction. BH's daily maximum oral usage dose is $200 \mathrm{mg}$ /day. Hallucinations, stimulation of central nervous system, excitation, hyperactivity, paranoia, dry mouth, and convulsions may occur in oral dosages of 500-3000 mg. Recreational use of benzydamine is popular in Poland and Brazil and recently some cases were reported from Turkey also $[3,4]$.

In this case report we present a young man that received high dose $\mathrm{BH}$ with alcohol and associated psychotic symptoms.

\section{Case Report}

A twenty-year-old man was admitted to emergency department with the complaint of acute visual hallucinations of seeing bugs. It was learned that he had received twenty capsules of Tantum (50 mg BH) orally (total dose of $1000 \mathrm{mg}$ ) with alcohol last night. However, it was thought that it was a suicidal attempt at first sight; then it was learned that he had misused $\mathrm{BH}$ with alcohol for its hallucinative effects. He expressed that he had learned this effect of $\mathrm{BH}$ from internet forum sites and bought the drug without prescription and that was the first misuse attempt of him. He denied any prior psychiatric disorder.

His vital signs were in normal ranges (BP: 120/70 mmHg, pulse rate: $80 / \mathrm{bpm}, \mathrm{SaO}_{2}: 96 \%$, and body temperature: $36.7^{\circ} \mathrm{C}$ ) and any neurologic deficit was not detected. Cognitive examination did not show any abnormality. In laboratory examination, ECG was normal sinus rhythm and there was not any abnormality in blood gas analysis, complete blood count, and routine biochemical measurements. Breathalyzer test was negative. Urine or blood drug screen was not obtained. 
The patient was referred to the psychiatry clinic for further evaluation and he was discharged without prescription within the same day. Patient could not be reached to ascertain whether the condition was resolved and there was not any record on further psychiatry clinic admission.

\section{Discussion}

$\mathrm{BH}$ preparates are over-the-counter in many countries and misuse reports are increasing $[5,6]$. In Turkey, BH preparates could be sold without prescription but Ministry of Health of Turkey prohibited selling $\mathrm{BH}$ preparates without prescription in 2012 after increased number of abusing cases. However, as seen in this case, the precautions seem not to be sufficient to prevent selling $\mathrm{BH}$ without prescription.

Hallucinations were reported as a frequent symptom after ingestion of benzydamine-containing vaginal preparations [5]. Doğan et al. reported a case report of visual hallucinations after $\mathrm{BH}$ overdose (total dose of $250 \mathrm{mg}, 14.7 \mathrm{mg} / \mathrm{kg}$ ) for suicide in a 11-year-old girl [4]. Our case was an adult man and took a total dose of $1000 \mathrm{mg}(14.2 \mathrm{mg} / \mathrm{kg}) \mathrm{BH}$ with alcohol for hallucinative effects.

All of the reported cases received $\mathrm{BH}$ orally as our case. Usage with alcohol is one of the reported ways of abusing $\mathrm{BH}$ and our case was also abusing $\mathrm{BH}$ with alcohol [3]. However it is hard to differentiate hallucinations from alcoholic hallucinosis; our patient was not an alcoholic and had visual hallucinations rather than auditory hallucinations.

Normal dose of BH may cause psychiatric side effects in patients who have psychiatric disorders, and overdose may result in chronic psychosis $[7,8]$. Our patient denied any prior psychiatric disorder.

$\mathrm{BH}$ is a widely used NSAID and psychotic symptoms were reported after abuse or overdose but there is no clear evidence how BH causes hallucinations mechanistically. These transient symptoms may result in fatal complications or chronic disorders. Physicians should be aware of psychotic adverse effects of $\mathrm{BH}$ and keep in mind these side effects while prescribing and evaluating patient especially patients with first-episode psychosis.

\section{Conflict of Interests}

The authors declared that they have no commercial, financial, or other relationships in any way related to the subject of this paper that might create any potential conflict of interests.

\section{References}

[1] R. S. Turnbull, "Benzydamine Hydrochloride (Tantum) in the management of oral inflammatory conditions," Journal Canadian Dental Association, vol. 61, no. 2, pp. 127-134, 1995.

[2] L. Gomez-Lopez, J. Hernandez-Rodriguez, J. Pou, and S. Nogue, "Acute overdose due to benzydamine," Human \& Experimental Toxicology, vol. 18, no. 7, pp. 471-473, 1999.

[3] E. S. Opaleye, A. R. Noto, Z. V. D. M. Sanchez, Y. G. De Moura, J. C. F. Galduróz, and E. A. Carlini, "Recreational use of benzydamine as a hallucinogen among street youth in Brazil," Revista Brasileira de Psiquiatria, vol. 31, no. 3, pp. 208-213, 2009.
[4] M. Doğan, C. Yilmaz, H. Çaksen, and A. S. Güven, "A case of benzydamine HCL intoxication," Eastern Journal of Medicine, vol. 11, no. 1-2, pp. 26-28, 2006.

[5] S. Ballesteros, M. F. Ramón, and R. Martínez-Arrieta, "Ingestions of benzydamine-containing vaginal preparations," Clinical Toxicology, vol. 47, no. 2, pp. 145-149, 2009.

[6] F. Schifano, O. Corazza, A. Marchi et al., "Analysis of online reports on the potential misuse of benzidamine," Rivista di Psichiatria, vol. 48, no. 3, pp. 182-186, 2013.

[7] M. K. Doksat, "Reversible worsening of psychosis due to benzydamine in a schizoaffective young girl who is already under treatment with antipsychotics," Bulletin of Clinical Psychopharmacology, vol. 19, no. 3, pp. 279-284, 2009.

[8] M. Guru, Y. Safak, E. Kuru, and S. Orsel, "Psychotic disorder related to benzydamine hydrochloride abuse: a case report," Bulletin of Clinical Psychopharmacology, vol. 22, no. 1, p. 51, 2012. 


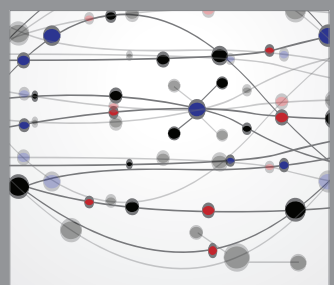

The Scientific World Journal
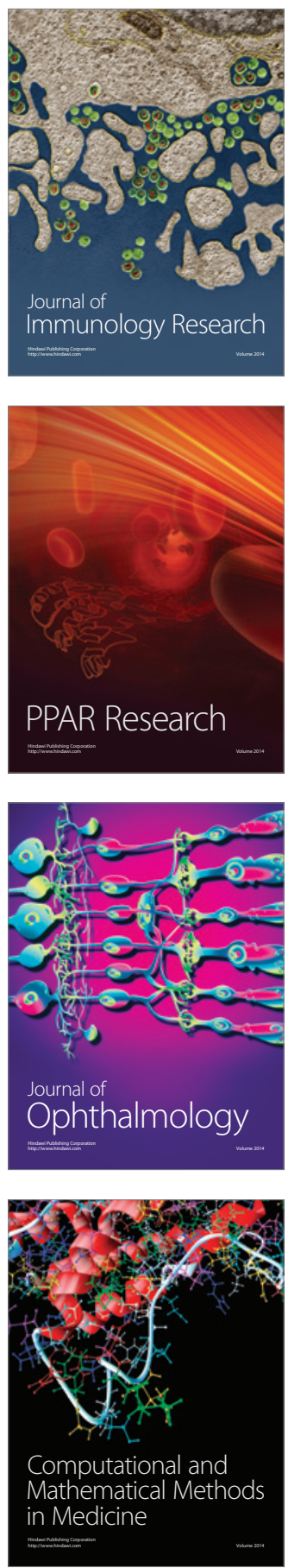

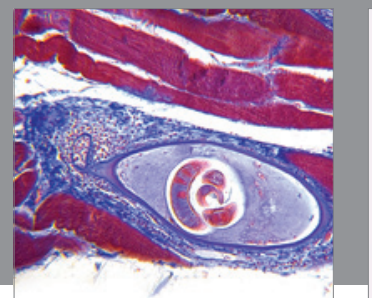

Gastroenterology

Research and Practice
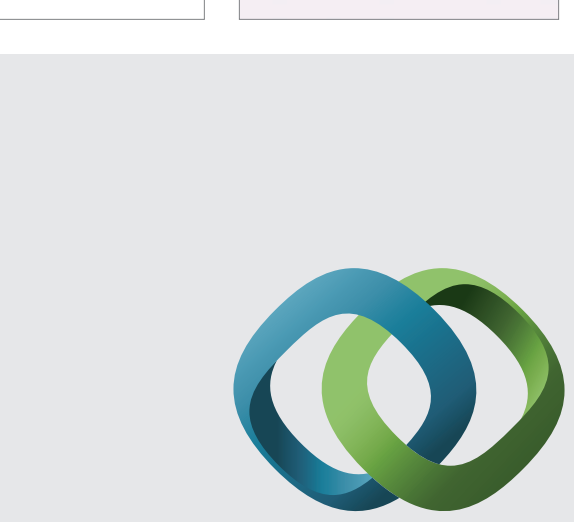

\section{Hindawi}

Submit your manuscripts at

http://www.hindawi.com
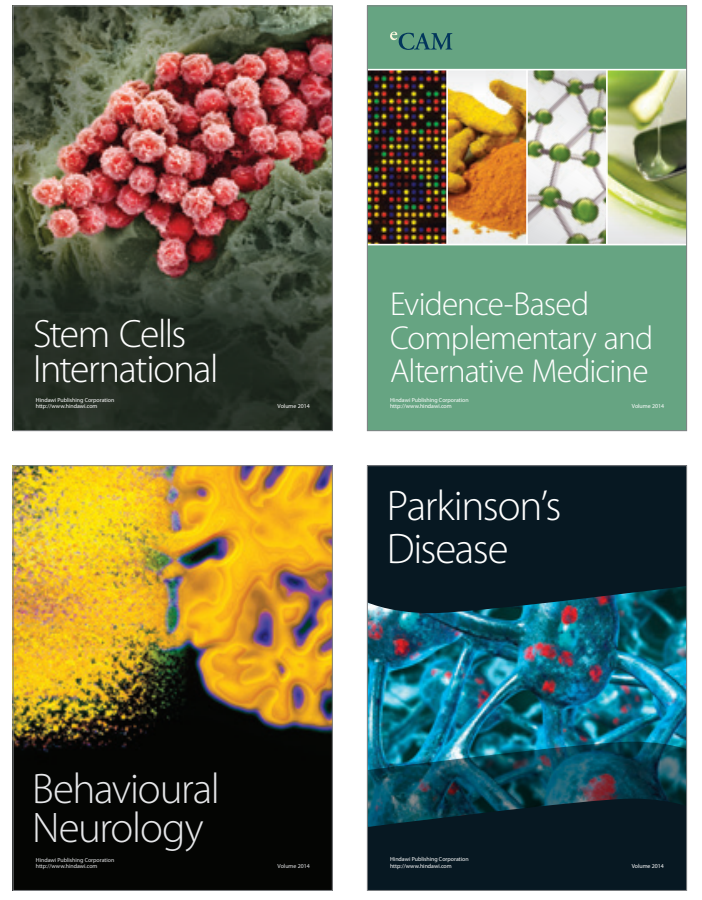
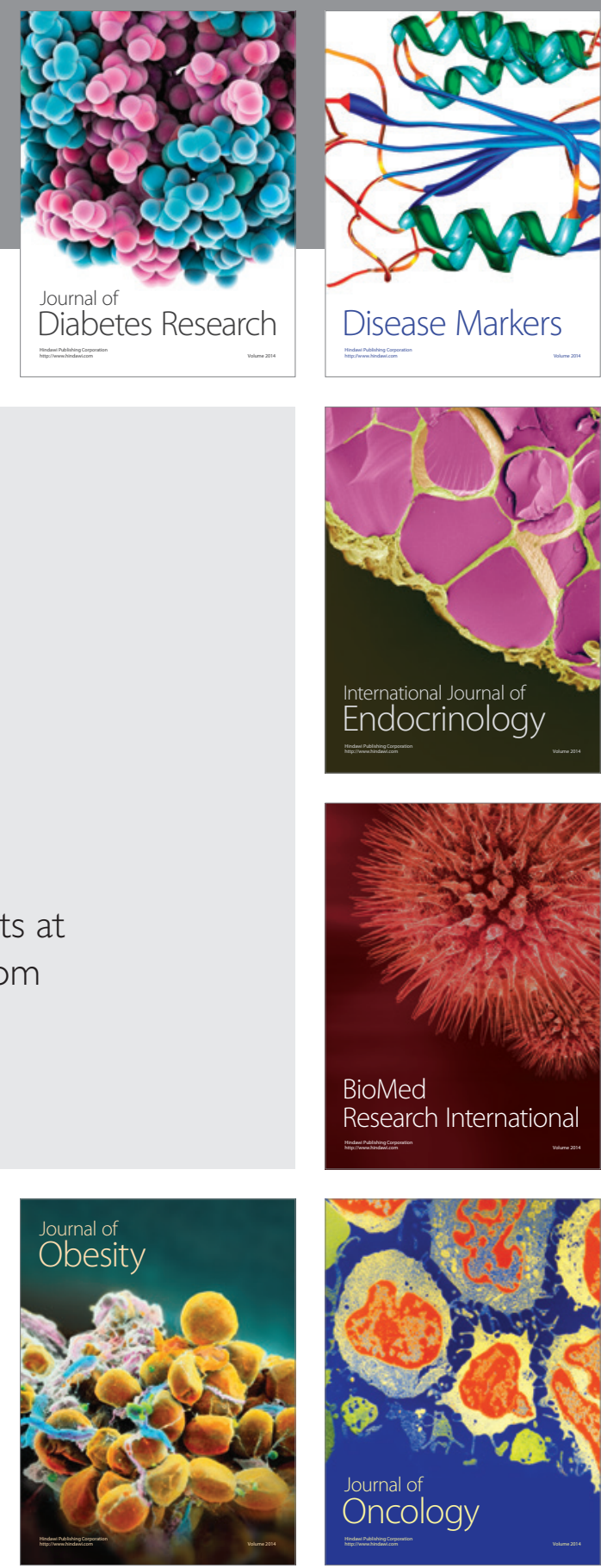

Disease Markers
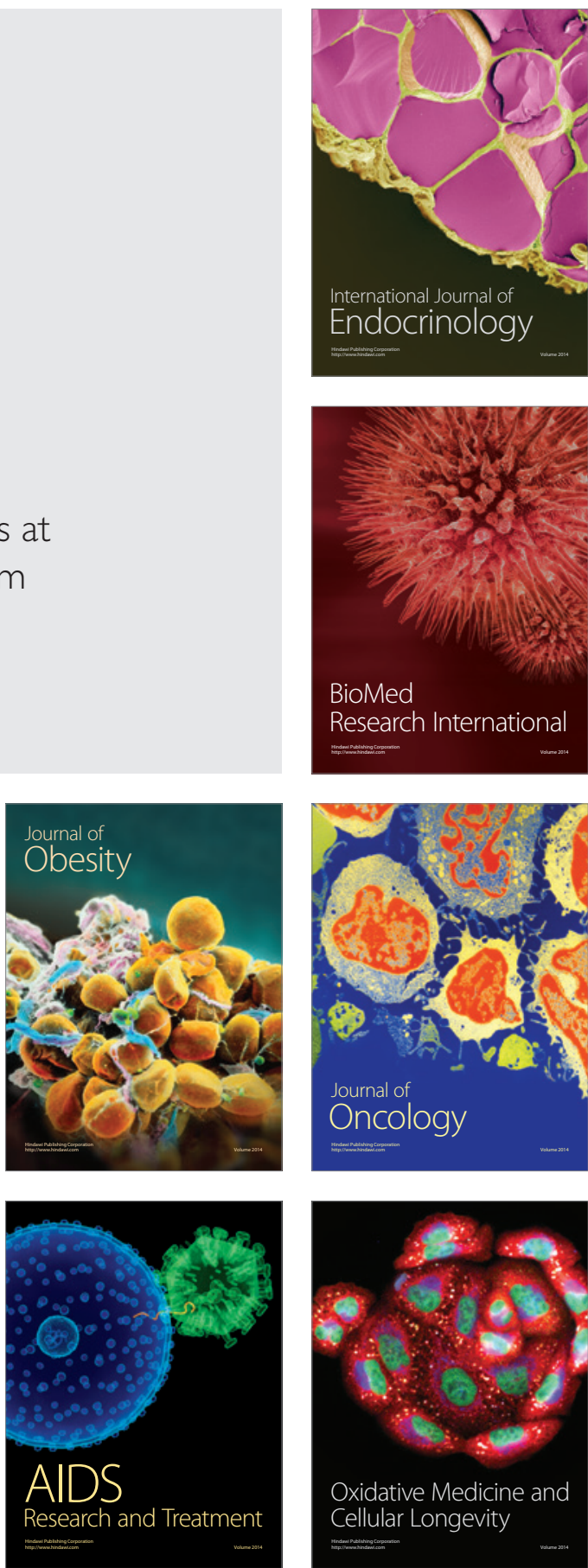